\title{
As vantagens logísticas e tributárias obtidas com a implantação do RECOF na indústria automobilística
}

\author{
Patrícia Guarnieri \\ LUIz OLíVIo BorTOLLI \\ Divonsir de Jesus da Silva Dutra \\ Kazuo Hatakeyama \\ UTFPR
}

\begin{abstract}
Resumo
A quebra de barreiras alfandegárias, que conduz as empresas à intensificação do comércio exterior exige maior desburocratização dos processos aduaneiros, visando a redução de custos logísticos e tributários. 0 Brasil abriga, atualmente, os principais grupos mundiais do segmento automobilístico, o que incrementa as exportações no setor. Recente estudo do Banco Mundial demonstra que enquanto os produtos brasileiros levam em média 39 dias para serem liberados, no restante do mundo, este trâmite é de apenas 27 dias. Para solucionar este problema, surgiu em 1997 o regime aduaneiro RECOF. O objetivo do presente artigo é analisar as vantagens logísticas e tributárias obtidas com a implantação deste regime no setor automobilístico. Trata-se de uma pesquisa aplicada e exploratória, cujo procedimento metodológico foi o estudo de caso. As principais vantagens proporcionadas por este regime são representadas pela redução dos custos logísticos e do capital de giro empregado no pagamento de impostos incidentes na compra de matérias-primas e insumos.
\end{abstract}

Palavras-chave

Logística, RECOF, Tributação.

\section{The logistics and tributaries advantages obtained with the implementation of the RECOF in the automotive industry}

\begin{abstract}
With the fall of customs barriers, that leads to the intensification of foreign commerce that demands greater reduction of bureaucracy in the customs processes, aiming at the reduction of logistics costs and tributes. Currently, Brazil shelters the main world-wide groups of automotive segment which develops the export business in this sector. A recent study of the World Bank demonstrates that, while the Brazilain products take in an average 39 days to gain permits, in the remaining of the world, this process takes only 27 days. To solve this problem, customs regimen RECOF appeared in 1997. The objective of the present article is to analyze the logistics advantages and taxes revenues with the implantation of this regimen in the automotive sector. This research is regarded as an applied and exploratory research, whereby the methodological procedure was a case study. The main advantages accrued from this regimen are represented by the reduction of the logistics costs and the return of the capital spent in the payment of the incident taxes in the purchase of raw materials and components.
\end{abstract}

Key words

Logistics, RECOF, Tributes. 


\section{INTRODUĈ̣̃O}

O novo ambiente concorrencial, que emergiu com maior força após a globalização dos mercados, conduz as empresas a freqüentes mudanças em seus sistemas produtivos e de atendimento aos clientes. Percebe-se a ênfase na melhora do nível do serviço logístico e na agilidade de resposta aos anseios dos consumidores.

A evolução da logística empresarial tem apresentado avanços significativos nos últimos anos por constituir-se em um dos fatores essenciais para a obtenção da competitividade das empresas. Dentre os diversos fatores que aceleraram este desenvolvimento, podem ser citados a pressão por maior giro, a redução de estoques, o atendimento a mercados distantes e a crescente inovação tecnológica.

A cadeia automotiva brasileira, incluindo veículos, peças e máquinas agrícolas, reúne 17 marcas e abriga os principais grupos mundiais do setor, incluindo norte-americanos, europeus e asiáticos. Essa cadeia é responsável por 4,5\% do PIB do Brasil e por $13,5 \%$ do PIB industrial. As exportações de veículos automotivos produzidos no Brasil foram de 897.079 unidades (ANFAVEA, 2005). Recente estudo do Banco Mundial e da Corporação Financeira Internacional, em 126 países, revelou que os produtos brasileiros levam, em média, 39 dias entre as porteiras das fazendas, portões de fábricas e os portos do País até o mercado consumidor, enquanto que no restante do mundo este trâmite é de 27 dias (SALES, 2006).

Com a finalidade de reduzir a burocracia, facilitando as importações e incentivando as exportações, o governo brasileiro instituiu através do Decreto Lei ${ }^{\circ} 2.412$, de 03 de dezembro de 1997, o Regime Aduaneiro Especial de Entreposto Industrial sob controle Informatizado - RECOF. Através da IN SRF n ${ }^{\circ} 254$ de 11 de dezembro de 2002, o regime foi expandido para o setor automobilístico, proporcionando uma série de vantagens.

Neste sentido, o objetivo do presente trabalho é analisar as vantagens logísticas e tributárias obtidas com a implantação do RECOF no setor automobilístico. Para atingir este objetivo, foi realizada uma pesquisa aplicada e exploratória, o procedimento metodológico utilizado foi o estudo de caso e a coleta de dados foi realizada através de observação direta e entrevista semi-estruturada com o responsável pelas áreas de Tecnologia de Informação (TI) e Logística da empresa DENSO do Brasil.

As principais vantagens proporcionadas pelo RECOF Automotivo são representadas pela redução dos custos logísticos e pela redução dos custos do capital de giro empregado no pagamento de impostos incidentes na compra de matérias-primas e insumos. Em um ambiente de negócios de intensa competitividade estes fatores tornam-se muito importantes na obtenção de vantagem competitiva.

\section{LOGÍSTICA E GERENCIAMENTO DA CADEIA DE SUPRIMENTOS [GCS]}

Em um universo de crescentes exigências em termos de produtividade e de qualidade do serviço oferecido aos clientes, as organizações passaram a se preocupar mais com a qualidade do fluxo de bens no processo produtivo, com o objetivo de atender bem o cliente e, conseqüentemente, fidelizá-lo. Para isso foi necessária a mudança nas estratégias empresariais. Uma das soluções encontradas para amparar estas mudanças foi a logística empresarial que, de acordo com Ballou (1993), estuda como a administração pode prover o melhor nível de rentabilidade nos serviços de distribuição aos clientes e consumidores, através do planejamento, organização e controles efetivos para as atividades de movimentação e armazenagem visando facilitar o fluxo de produtos.

A logística busca alternativas para a redução do tempo necessário para reunir as diversas quantidades de recursos disponíveis no mercado e para reduzir a distância entre a produção e os diversos consumidores espalhados em amplas regiões geográficas. Assim, o principal objetivo da logística é a redução dos custos existente entre a produção e a demanda, de modo que os consumidores tenham bens e serviços quando e onde quiserem, em perfeitas condições e a um preço razoável.

Christopher (1997) afirma que logística é o processo de gerenciar estrategicamente a empresa, na aquisição, movimentação e armazenagem de matérias-primas, peças, produtos acabados e demais materiais, além dos fluxos de informações recíprocos, através da organização de seus canais de marketing, tornando possível a maximização das lucratividades presentes e futuras através do atendimento dos pedidos dos clientes a custos reduzidos.

O desempenho logístico tem papel importante nos negócios das organizações, porque pode afetar sensivelmente os custos, resultados e níveis de serviço aos clientes que são continuamente modificados pela dinâmica dos mercados, gerando transformações que influenciam diretamente no funcionamento satisfatório dos fluxos de bens, serviços e informações no âmbito da empresa, resultando em diferencial competitivo. Descobertas tecnológicas e mercados emergentes abrem novos caminhos para a reorganização, adaptação e otimização do fluxo de matérias-primas, semi-acabados, peças sobressalentes e materiais reciclados (DORNIER et al., 1998).

Quando se trata de logística internacional, os riscos em termos de tempo e estoques são mais complexos, conforme Harrison e Van Hoek (2003), os principais desafios que devem ser levados em consideração e que diferenciam a logística internacional da local são:

1) Maior tempo na obtenção de recursos e suprimento - O 
tempo de trânsito de recursos e suprimentos internacionais são maiores devido ao prazo necessário à cobertura de segurança e ao prazo legal estabelecido para o desembaraço aduaneiro, o que leva a uma maior retenção de estoques.

2) Múltiplos pontos de consolidação e decomposição Múltiplos tipos de fretes e opções de custos podem proporcionar economias de escala. As economias de escala podem ser obtidas quando os bens produzidos em diversas fábricas são agrupados e consolidados para um transporte comum.

Além destes desafios, percebe-se a necessidade de maior intercâmbio de informações entre as empresas envolvidas nas negociações internacionais, o que pode ser proporcionado com o auxílio das tecnologias de informação e também a constituição de parcerias ao longo da rede que permitem identificar e resolver problemas potenciais antes que estes ocorram.

Atualmente a logística atua como elo de integração das atividades dos fluxos de materiais e produtos. Para Arbache et al. (2004), o conceito de logística integrada é uma forma organizada de perceber todos os processos que geram valor para o cliente final, independentemente do local de execução. Pode ser executado na própria empresa ou em alguma outra com a qual há algum tipo de relacionamento.

A mudança de percepção no gerenciamento logístico e a necessidade de se considerar todas as empresas envolvidas no objetivo de atender o consumidor, não só nos processos internos, conduziu ao desenvolvimento do conceito de gerenciamento da cadeia de suprimentos (GCS).

O conceito de GCS, de acordo com Christopher (1997), é entendido como a gestão e a coordenação dos fluxos de informações e materiais entre a fonte e os usuários como um sistema, de forma integrada. A ligação entre cada fase do processo, na medida em que os produtos e materiais se deslocam em direção ao consumidor é baseada na otimização, ou seja, na maximização do serviço ao cliente, enquanto se reduzem os custos e os ativos retidos no fluxo logístico.

Pires (2004) salienta que em muitos setores industriais, já não é mais suficiente apenas integrar as operações, estruturas e infra-estruturas internas com a estratégia competitiva, a tendência é a integração dos processos internos, chave da empresa, com fornecedores externos e clientes, formando uma cadeia de suprimentos (CS) com propósitos e procedimentos bem definidos e consistentes. Desta forma, a vantagem competitiva obtida juntamente, ao longo da CS torna-se mais difícil de ser ultrapassada pelos concorrentes.

Dornier et al. (1998), refere-se aos esforços dos parcei- ros da cadeia de suprimentos para coordenar e gerenciar suas atividades como uma única entidade unificada, do que como entidades separadas. A idéia principal é que mercados industriais são formados por fornecedores e clientes ou, mais genericamente, por compradores e vendedores. Ultimamente, os relacionamentos são benéficos para todas as partes envolvidas. O sucesso completo da integração da cadeia de suprimentos requer das partes sua parcela de conhecimento sobre recursos, organização, estratégias e assim por diante. Através do compartilhamento desta informação, as empresas podem otimizar o canal total, eliminando redundâncias e outras ineficiências que adicionam custos sem adicionar valor nas atividades logísticas.

\section{governo brasileiro instituiu através do Lei $n^{0} 2.412$, o Regime Aduaneiro Especial de Entreposto Industrial sob controle Informatizado - RECOF.}

De acordo com Harrison e Van Hoek (2003), as cadeias de suprimentos globais tornam-se mais complexas pela incerteza e dificuldade de controle. A incerteza decorre de tempos mais longos despendidos nas atividades logísticas, da falta de conhecimento dos riscos, das condições dos mercados a serem atendidos e, desta forma, a coordenação torna-se complicada, principalmente, devido ao maior número de etapas de distribuição, intervenção dos governos locais por intermédio da alfândega e de barreiras comerciais.

No caso de empresas que operam em um segmento tão complexo quanto o automotivo, no qual pequenas falhas podem prejudicar toda a cadeia onerando-a com custos desnecessários, são prementes ações no sentido de agilizar os processos entre montadoras e fornecedores, reduzindo custos e proporcionando vantagem competitiva sustentável. Algumas atividades logísticas absorvem uma parcela considerável dos custos envolvidos em uma cadeia de suprimentos e o desenvolvimento e implementação de práticas de melhoria nestas atividades proporcionam ganhos substanciais. No próximo tópico são descritas estas atividades.

\section{ATIVIDADES LOGÍSTICAS NA CADEIA DE SUPRIMENTOS}

Um recente estudo realizado pelo Centro de Estudos em Logística/Coppead demonstra que a composição de todos os custos logísticos do Brasil em 2004 chega a um total de R\$ 222 bilhões, o equivalente a 12,6\% do PIB, enquanto que nos Estados Unidos os custos logísticos (domésticos) 
equivalem a $8,26 \%$ do PIB. Entre os custos das atividades, o de estoque é relativamente o que apresenta a maior diferença na comparação, 3,9\% no Brasil contra $2,1 \%$ nos EUA (LIMA, 2006).

Lima (2006), responsável por este estudo, afirma que o elevado custo do estoque brasileiro deve-se ao elevado custo de capital. O autor também afirma que o principal motivo do custo logístico no Brasil ser superior ao americano está relacionado, principalmente, à menor participação de serviços na nossa economia e menor valor agregado dos nossos produtos, além do alto custo de capital. É importante ressaltar, ainda de acordo com Lima (2006), que os valores de frete rodoviário praticados no Brasil são bastante baixos; no entanto, a falta de infra-estrutura adequada, aliada aos problemas de capacidade e disponibilidade, muitas vezes inviabiliza o transporte de cargas por outros modais, muitas vezes mais adequados à distância e ao tipo de produto. Assim, o resultado acaba sendo um frete alto para quem paga, mas baixo para quem recebe.

Todos estes fatores influenciam, sensivelmente, o nível de serviço logístico, os preços dos produtos e acabam por comprometer o bom andamento do processo logístico. Para se obter sucesso neste processo, conforme Pozo (2002) é essencial que se disponha de um sistema de informações que possa satisfazer a todos os requisitos que compõem sua estrutura, atendendo com a rapidez das respostas os desejos e as necessidades dos consumidores. A administração de materiais, o planejamento da produção, o suprimento e a distribuição física integram-se para formar este novo conceito de gerenciar os recursos, fundamentais para atender aos desejos do cliente.

As atividades administradas pela logística empresarial podem ser divididas em atividades primárias ou chaves e atividades de apoio ou suporte. As atividades primárias, segundo Ballou (1993, p.24), englobam o processamento de pedidos dos clientes, transportes e administração de estoques e são consideradas essenciais para o desempenho da empresa, além de contribuírem com a maior parcela do custo total da logística. Também apresentam importância primária para que se atinjam os objetivos logísticos de custo e nível de serviço.

Porém, somente estas atividades não são suficientes para atingir o nível de serviço desejado pelos clientes. Para isso existem as atividades de apoio, que contribuem no suporte às atividades primárias. Segundo Ballou (1993), as atividades de apoio são: armazenagem, manuseio de materiais, suprimentos, embalagem, manuseio de mercadorias devolvidas e também os sistemas de informação.

Considerando que, no processo de produção de determinado produto ou serviço, todas estas atividades são envolvidas e por sua vez geram custos, há necessidade de se analisar não somente o processo de uma empresa isolada- mente, mas sim da sua cadeia de suprimentos como um todo. Desta forma, é possível detectar quais atividades podem ter seus processos racionalizados, o que reduz sensivelmente os custos logísticos e maximiza a rentabilidade de todas as empresas envolvidas no processo.

A internacionalização das redes logísticas gera conseqüências para as políticas das atividades de manutenção de estoques, manuseio e transporte. As principais implicações logísticas no comércio global, de acordo com Harrison e Van Hoek (2003, p. 148), envolvem:

- a localização de produtos e serviços para atender a determinadas necessidades de mercado gera implicações para o estoque, manuseio e transporte;

- o tempo para chegar ao mercado pode alongar-se, em razão de maiores distâncias e complexidade de rede. A obsolescência de produtos e os custos de retenção de estoques precisam ser gerenciados de diferentes maneiras;

- o foco da fabricação precisa ser repensado para abranger novos mercados, bem como novas estratégias de entrega.

Tendo em vista que, para as empresas exportadoras e importadoras, fatores como retenção de mercadorias na alfândega e paralisações da Receita Federal oneram a cadeia de suprimentos, além de interromper seu processo produtivo e gerar custos substanciais com manutenção de estoques em trânsito, manuseio e transporte de mercadorias, faz-se necessária a implementação de regimes aduaneiros eficazes que minimizem os inconvenientes na exportação e importação. Para reduzir a burocracia nas negociações internacionais, foi instituído em 1997 o Regime Aduaneiro de Entreposto Industrial sob controle informatizado, o qual será detalhado na seção seguinte.

\section{RECOF - REGIME ADUANEIRO DE ENTREPOSTO INDUSTRIAL SOB CONTROLE INFORMATIZADO}

Instituído pelo DL no 2.412 (1997) o RECOF permite a importação de mercadorias para operações de industrialização de produtos destinados ao mercado externo, com a suspensão do pagamento de impostos. Os impostos suspensos são representados pelo Imposto de Importação (II), pelo Imposto sobre Produtos Industrializados (IPI), pela contribuição para o Programa de Integração Social (PIS) e pela Contribuição para Financiamento da Seguridade Social (Cofins).

O RECOF para o setor automotivo é regulamentado pela IN SRF 254 (2002), onde são suspensos os pagamentos do Imposto de Importação (II) e o Imposto sobre Produtos Industrializados (IPI). As suspensões tratadas pela referida Instrução Normativa referem-se às mercadorias importadas e adquiridas no mercado interno destinadas à industrialização de produtos para exportação. 
Trata-se de um regime especial (RECOF Automotivo) que objetiva a redução da burocracia no comércio internacional, facilitando as importações e incentivando as exportações. As principais vantagens oferecidas pelo regime são representadas pela agilidade no processo de desembaraço aduaneiro nas importações, redução nos custos do capital de giro, otimização do fluxo de caixa e redução dos custos de armazenagem.

Este regime difere do programa Linha Azul, que segundo Sales (2006) é um programa aduaneiro especial criado para grandes exportadores de manufaturados. Esse programa consiste em transferir a responsabilidade da fiscalização das importações do governo para as empresas. O principal objetivo do programa é o desembaraço aduaneiro automático de produtos que se destinam à importação e exportação. Neste, uma estrutura de auditoria interna/externa certifica o cumprimento de todos os requisitos determinados pela legislação aduaneira. Porém, neste regime não há o benefício da suspensão de impostos.

O processo de desembaraço aduaneiro pelo RECOF Automotivo é informatizado, proporcionando a liberação da carga nos portos e aeroportos, no máximo em 24 horas. A entrada de matérias-primas e componentes importados é garantida, sem a necessidade de passar pelo processo aduaneiro habitual, evitando a retenção dos itens por imprevistos, como, por exemplo, uma paralisação na Secretaria da Receita Federal, além do benefício da suspensão de impostos (II e IPI).

Desta forma, as autoridades aduaneiras evitam a retenção dos produtos por maior tempo e as empresas credenciadas podem manter baixos níveis de estoques, para um abastecimento Just-in-time, reduzindo os custos com armazenagem, aumentando o giro das mercadorias estocadas e agilizando a distribuição dos produtos no mercado. A contrapartida exigida pela legislação vigente é que seja dado à Secretaria da Receita Federal o acesso total aos arquivos da empresa. Esse acesso é proporcionado pelo sistema front-end via Internet sendo necessário que todas as informações estejam atualizadas e corretas.

Além da agilidade proporcionada, Portugal (2006) afirma que existe ainda o compartilhamento do regime com os fornecedores, ganhos de fluxo de caixa com o pagamento dos impostos somente no momento da venda no mercado nacional (se o bem não for exportado), redução das taxas de armazenagem e controle informatizado do processo.

Nas operações habituais de importação de produtos que no processo industrial compõem outros produtos destinados ao mercado externo, no desembaraço aduaneiro é exigido o pagamento do Imposto de Importação (II) e do Imposto sobre Produtos Industrializados. As empresas poderão creditar esses impostos pagos na compra (importação), no momento da exportação. Esses créditos são compensados quando do pagamento dos mesmos impostos devidos, em operações realizadas internamente (DUTRA, 2006).

Para as empresas que integram o RECOF Automotivo, o Imposto de Importação (II) e o Imposto sobre Produtos Industrializados (IPI) não são cobrados, desde que comprovadamente componham outro produto que se destine ao mercado exterior. Se o produto do qual o bem importado faz parte se destinar ao mercado interno, os impostos incidentes sobre a importação serão pagos quando de sua venda (IN $\mathrm{SRF}$ n- 254, 2002).

\section{A s principais vantagens proporcionadas pelo pela redução dos custos logísticos e pela redução dos custos do capital de giro.}

$\mathrm{Na}$ compra de matérias-primas e insumos nacionais que venham comprovadamente fazer parte de um produto destinado à exportação, o IPI incidente na operação é suspenso. Quando da exportação efetiva do produto o pagamento do IPI suspenso fica definitivamente dispensado. Se o destino do produto final for o mercado interno, o IPI será devido quando da venda (IN SRF no 254, 2002, art. 27).

Nas operações habituais de compra de matérias-primas e insumos nacionais, para comporem produtos finais destinados ao mercado interno ou externo, o IPI é pago na compra destes. Na realidade, o IPI faz parte do preço de compra. Quando da venda do produto final (mercado interno ou externo) a empresa se credita do IPI pago na compra das matérias-primas e insumos. Nas exportações, o crédito pode ser compensado no IPI devido sobre a venda para o mercado interno. Nas operações internas, como a empresa pagou o IPI na compra, poderá creditar-se deste, quando devido na venda do produto final (DUTRA, 2006).

A principal dificuldade da maioria das empresas em se integrar no regime RECOF está na organização de processos e integração sistêmica. Especificamente, no caso das indústrias automotivas, existem ainda muitos fornecedores e montadoras com esta dificuldade. O fluxo do processo de liberação alfandegária através do RECOF Automotivo pode ser visualizado através da Figura 1.

A tendência é que esta modalidade seja um fator de sobrevivência no setor de autopeças, pois, conforme demonstra a Figura 1, além da rápida liberação de insumos importados, 
os impostos são suspensos até a venda do produto acabado, por um período de até um ano. Para os produtos a serem exportados ou vendidos para clientes habilitados no RE$\mathrm{COF}$, os impostos relativos à importação ficam isentos de pagamentos e os destinados para o mercado interno são corrigidos somente pela variação da respectiva alíquota e/ ou variação cambial de moedas estrangeiras.

De acordo com Portugal (2006), o papel do RECOF é vital para o País, pois não se limita às questões econômicas, mas repercute também em ganhos logísticos para as empresas que se utilizam desse regime. Criado com o objetivo de estimular e facilitar as operações de importação e exportação das empresas, dando maior competitividade e agilidade para seus produtos e insumos nas trocas comerciais internacionais, o regime tem ajudado muitas empresas a reduzir seus custos com logística e impostos.

O sistema também proporciona a redução do custo de oportunidade incidente sobre o nível de estoque. Segundo Bornia (2002), o custo de oportunidade é o valor que se deixa de ganhar ao se optar por um investimento menos rentável que um outro. De outra forma, sabendo-se da existência do custo do capital, independente de ser próprio ou de terceiros, os custos de oportunidade podem ser representados pelo menor desembolso na aquisição da mesma quantidade de matéria-prima ou insumo.
O RECOF Automotivo proporciona a oportunidade de redução do custo de oportunidade na aquisição da matériaprima e insumos e, em conseqüência, dos estoques desses e de produtos finais, tendo em vista a suspensão do Imposto sobre os Produtos Industrializados e do Impostos de Importação. Aos valores não despendidos com esses impostos apresentam-se como alternativas mais rentáveis, como, por exemplo, a aquisição de uma quantidade maior de matériaprima para aproveitamento de câmbio favorável, aplicações financeiras, entre outras.

Desta forma, o RECOF agiliza o desembaraço de mercadorias direcionadas ao comércio exterior, ao mesmo tempo em que reduz os custos alfandegários, de oportunidade e simplifica o gerenciamento logístico de armazenamento, transporte e distribuição, atividades estas que oneram a maior parcela dos custos logísticos nas cadeias de suprimentos.

O RECOF Automotivo, instituído pela IN SRF 254 (2002), é resultado das negociações entre ANFAVEA - Associação Nacional dos Fabricantes de Veículos Automotores e a Receita Federal. De acordo com o presidente da Anfavea, o novo regime vai desburocratizar as importações, agilizando e desonerando a aquisição de componentes, o que proporcionará aumento da competitividade às empresas exportadoras do setor automotivo.

Figura 1: Fluxo do processo de liberação alfandegária através do RECOF.

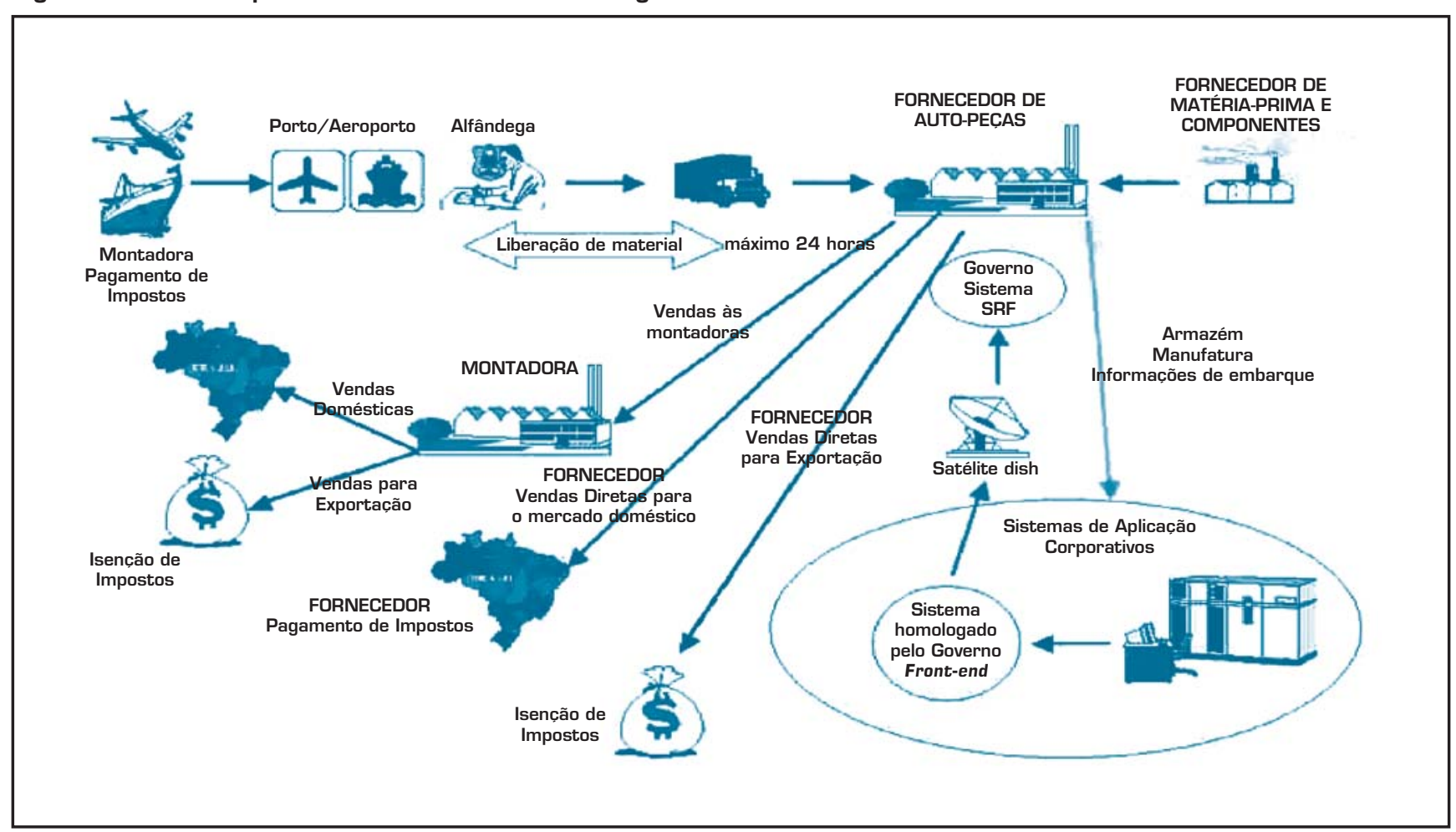

Fonte: Os autores (2005). 
Segundo o diretor institucional da Anfavea (2005), antes, a empresa precisava recolher os impostos das peças importadas para, só depois, deduzir os valores pagos, no momento da exportação. Agora, as montadoras e fornecedores de autopeças informam antecipadamente o que será usado em produtos exportados, deixando de recolher os impostos na importação.

Para se beneficiar do RECOF Automotivo, a empresa deve manifestar seu interesse à Secretaria da Receita Federal, aderindo ao programa por meio de um software. O setor automotivo é o terceiro segmento beneficiado com um regime aduaneiro especial para empresas com potencial para alavancar exportações. Os outros foram os segmentos de informática e aeronáutico.

\section{Critérios para a concessão do RECOF}

Os critérios adotados pela Secretaria da Receita Federal para a concessão do RECOF, tratados pelo art. 2 da IN SRF no 254 (2002), baseiam-se nas modalidades de operações industriais. Essas modalidades são constituídas por:

- Montagem de veículos ou de outros produtos da indústria automotiva, relacionados no Anexo I da referida Instrução Normativa;

- Transformação, beneficiamento e montagem de partes e peças utilizadas na montagem dos produtos relacionados no Anexo I da IN SRF no 254 (2002);

- Acondicionamento e recondicionamento de partes e peças para serem comercializadas no mesmo estado em que foram importadas.

Também podem ser admitidos no RECOF, os seguintes produtos:

- Produtos relacionados no Anexo I da IN SRF no 254 (2002) para serem submetidos a testes de performance, resistência ou funcionamento e os utilizados no desenvolvimento de produtos da indústria automotiva;

- Motores e transmissões usados, para serem submetidos à operação de renovação, recondicionamento, manutenção e reparo;

- Peças ou partes de peças a serem aplicadas nas operações descritas acima.

O principal requisito para operar no regime RECOF, conforme o art. 4음 IN SRF no 254 (2002) é a habilitação da empresa na Secretaria da Receita Federal. Para obter essa habilitação a empresa deve se caracterizar como montadora de veículos ou fabricante dos demais produtos constantes do Anexo I da referida Instrução Normativa ou ser fabricante de partes e peças para tais produtos.

Além de apresentar reconhecida idoneidade fiscal, as empresas deverão apresentar um patrimônio líquido igual ou superior a $\mathrm{R} \$ 25.000 .000,00$ (vinte e cinco milhões de reais), de acordo com a IN 417 (2004) e um sistema informatizado de controle de entrada e saída de mercadorias. Esse sistema deverá controlar todos os registros de apuração de créditos tributários devidos, extintos ou com exigibilidade suspensa, integrando os sistemas corporativos da empresa e a sua contabilidade, com livre e permanente acesso da Secretaria da Receita Federal.

\section{RECOF Automotivo objetiva a redução da burocracia no comércio nternacional, facilitando as importações incentivando as exportações.}

As empresas interessadas no RECOF deverão assumir o compromisso de realizar exportações anuais de no mínimo US\$ 20,000,000.00 (vinte milhões de dólares americanos). Essas exportações referem-se a produtos que contenham os componentes objetos do RECOF (IN SRF № 254, Art. 6o, 2002).

A habilitação conjunta dos fornecedores industriais de partes, peças e componentes para a linha de produção (Anexo I da IN SRF 254, 2002), inclusive os nacionais, também é prevista pela IN SRF no 254 (2002). A co-habilitação referese aos fornecedores de produtos nacionais ou produzidos no país com matérias-primas, partes e peças importadas, destinados à linha de produção das empresas tratadas pelo RECOF. Neste caso, não serão exigidos o patrimônio líquido mínimo, o sistema informatizado de controle e o compromisso mínimo de exportação.

Julgou-se importante a diferenciação do Regime Aduaneiro de Entreposto Industrial sob controle Informatizado - RECOF, objeto do presente trabalho, do Regime Drawback. Os principais aspectos referentes a este último serão apresentados na próxima seção.

\section{Regime de Drawback}

O Drawback é um procedimento aduaneiro que possibilita ao produtor importar insumos sem a incidência de impostos, desde que estes insumos sejam utilizados na produção de bens exportáveis. Este regime foi instituído em 1966 pelo Decreto Lei no 37, de 21/11/66 e seu mecanismo funciona como um incentivo às exportações, pois reduz os custos de produção de produtos exportáveis, tornando-os mais competitivos no mercado internacional. Está também descrito no Regulamento Aduaneiro e na Portaria 4/97 da Secretaria do Comércio Exterior (SECEX), onde consta 
a sistemática administrativa e operacional do benefício. (HAMAD, 2006).

Segundo Brito Júnior (2004), o benefício do Drawback compreende a suspensão, isenção ou restituição de impostos que compreende: o Imposto de Importação (II), o Imposto sobre Produto Industrializado (IPI), o Imposto sobre as Operações relativas à Circulação de Mercadorias e sobre a Prestação de Serviços de Transporte Interestadual e Intermunicipal e de Comunicação (ICMS), conforme definido pelos Estados e Distrito Federal, inclusive no âmbito do CONFAZ, o Adicional ao Frete para Renovação da Marinha Mercante (AFRMM). As importações amparadas no regime não estão sujeitas ao exame de similaridade nem à obrigatoriedade de transporte em navio de bandeira brasileira.

De acordo com a Secretaria da Receita Federal (2006), existem três modalidades de drawback: isenção, suspensão e restituição de tributos. A primeira modalidade consiste na isenção dos tributos incidentes na importação de mercadoria, em quantidade e qualidade equivalentes, destinada à reposição de outra importada anteriormente, com pagamento de tributos, e utilizada na industrialização de produto exportado. A segunda, na suspensão dos tributos incidentes na importação de mercadoria a ser utilizada na industrialização de produto que deve ser exportado. A terceira trata da restituição de tributos pagos na importação de insumo importado utilizado em produto exportado. O drawback de restituição praticamente não é utilizado. $\mathrm{O}$ instrumento de incentivo à exportação em exame compreende, basicamente, as modalidades de isenção e suspensão.

Brito Júnior (2004) ressalta que a devolução dos tributos é concedida sob a forma de crédito fiscal à importação no valor recolhido por meio de Declaração de Importação, a ser utilizado em qualquer importação posterior. $\mathrm{O}$ autor ainda afirma que o texto da legislação pertinente também tece as seguintes considerações gerais:

1) O regime de drawback poderá ser concedido a empresas industriais, agroindustriais, ou comerciais. Devem ser observadas as seguintes proporções:

- Relação Importação x Exportação: 40\% importado e $60 \%$ nacional

- Perda: máxima 5\%

2) Em operações especiais, a isenção poderá ser concedida nos seguintes casos:

- Drawback genérico, exclusivo na modalidade suspensão, que se caracteriza pela discriminação genérica da mercadoria a importar e o seu respectivo valor.

- Drawback sem cobertura cambial, também exclusivo na modalidade suspensão e que se caracteriza pela não cobertura cambial, parcial ou total, da importação.

- Drawback solidário, exclusivo na modalidade suspensão, e que é caracterizado pela participação solidária de uma ou mais empresas industriais.
- Drawback intermediário, concedido para suspensão e isenção e é definido pela importação de mercadoria destinada a processo de industrialização de produto intermediário a ser fornecido a empresas industriais exportadoras, para emprego na industrialização de produto final destinado à exportação.

- Drawback para embarcação, concedido para suspensão e isenção que se caracteriza pela importação de mercadoria destinada a processo de industrialização de embarcação para fins de venda no mercado interno.

- Drawback para fornecimento no mercado interno, para a modalidade de suspensão e é caracterizado pela importação de matéria-prima, produto intermediário e componentes destinados a processo de industrialização no país, de máquinas e equipamentos a serem fornecidos no mercado interno, em decorrência de licitação internacional.

- Drawback para reposição de matéria-prima nacional, exclusivo na modalidade isenção e que se define pela importação de mercadoria para reposição de matériaprima nacional utilizada no processo de industrialização de produto exportado.

O benefício, ainda de acordo com Brito Júnior (2004), é concedido pela Secretaria de Comércio Exterior (Secex) do Ministério do Desenvolvimento, Indústria e Comércio Exterior, mediante Ato Concessório. O Ato Concessório é para a importação de mercadoria destinada à industrialização de bem de capital de longo ciclo de produção e o prazo de validade do Ato Concessório de drawback deverá ser compatível com a industrialização e exportação do produto, prorrogável até o prazo limite de 5 (cinco) anos.

A concessão do Regime Especial de Drawback não assegura a obtenção de cota de importação para mercadoria ou de exportação para produto sujeito a contingenciamento, nem exime a importação e a exportação da anuência prévia de outros órgãos, quando for o caso. Também não pode ser concedido o regime de drawback para importação de mercadoria utilizada na industrialização de produto destinado ao consumo na Zona Franca de Manaus e em áreas de livre comércio, para importação ou exportação de mercadoria suspensa ou proibida, para exportações contra pagamento em moeda nacional e em moeda-convênio ou outras nãoconversíveis, para importação de petróleo e seus derivados, conforme o disposto no Decreto $\mathrm{n}^{\mathrm{o}} 1.495$, de 18 de maio de 1995, e para exportações vinculadas à comprovação de outros Regimes Aduaneiros ou incentivos à exportação. (SECRETARIA DA RECEITA FEDERAL, 2006).

Basicamente, os regimes drawback e RECOF são muito semelhantes, a grande diferença está na liberação do material na alfândega, pois no segundo esta é feita sempre em canal verde (modalidade de liberação de importação imediata), 
o que leva aproximadamente 24 horas, e no primeiro em canal amarelo (modalidade de liberação de importação com verificação de documentação), com prazo de 7 a 15 dias úteis. Além de que para cada importação no regime Drawback é necessário emitir um ato concessório, enquanto que no regime RECOF isso não ocorre. O RECOF não é vulnerável em casos de paralisações da Receita Federal, já o Drawback é suscetível a este fato. Desta forma, o RECOF possibilita à empresa manter um inventário de materiais mais enxuto, não necessitando de estoque de segurança para cobrir eventuais paralisações, retenção de materiais na alfândega, entre outras. $\mathrm{O}$ regime drawback pode ser utilizado por vários segmentos, entretanto, o RECOF é um regime aduaneiro destinado somente para os segmentos de informática, telecomunicações, automotivo e aeronáutico.

\section{METODOLOGIA}

O presente artigo foi elaborado através do método indutivo que fornece bases lógicas à investigação. Segundo Gil; Lakatos e Marconi apud Silva e Menezes (2001), no raciocínio indutivo a generalização deriva de observações de casos da realidade concreta. As constatações particulares levam à elaboração de generalizações. Do ponto de vista de sua natureza foi realizada uma pesquisa aplicada que, segundo Silva \& Menezes (2001), objetiva gerar conhecimentos para aplicação prática dirigidos à solução de problemas específicos do cotidiano. Envolve verdades e interesses locais. É também exploratória, pois trava um maior conhecimento do problema, através, por exemplo, de pesquisas bibliográficas e estudo de caso.

O procedimento metodológico utilizado foi o estudo de caso, considerando-se que o foco de interesse da pesquisa está voltado para fenômenos atuais, analisados dentro do contexto real da empresa objeto do estudo, uma indústria automobilística. Para Gil (1999) o estudo de caso envolve o estudo profundo de um ou poucos objetos de maneira que se permita o seu conhecimento detalhado. Para corroborar esta idéia, Yin (2001) afirma que o estudo de caso possibilita que o pesquisador realize uma investigação que preserve as características holísticas e significativas da vida real que podem ser estudadas mais profundamente através deste procedimento técnico.

Destacou-se para o estudo de caso, uma empresa considerada representativa no segmento automotivo, devido ao motivo de, freqüentemente, ser pioneira entre os fornecedores da indústria automotiva, no que tange à implementação de práticas e inovações tecnológicas. Trata-se da empresa DENSO do Brasil, fabricante de sistemas térmicos que são fornecidos para as principais montadoras de veículos estabelecidas no país: Volkswagen, Toyota, Honda, Fiat, Daimler Chrysler, Ford, General Motors, Iveco, Volvo, Scania, Renault, CNH e John Deere. Enquadra-se como uma empresa de grande porte, cujo faturamento anual gira em torno de US\$ 160 milhões, dedica-se também ao mercado internacional, exportando e importando um volume considerável de peças, componentes e produtos acabados. Possui filiais em Manaus-AM, Betim-MG, Pindamonhangaba-SP e Argentina, tendo sua sede em Curitiba-PR.

\section{processo de desembaraço aduaneiro proporcionando a liberação da carga nos portos e aeroportos, no máximo em 24 horas.}

A coleta de dados deste procedimento técnico inclui foram: observação direta, entrevista semi-estruturada e coleta documental. Para tanto, foram realizadas visitas técnicas semanais na referida empresa, objeto do estudo, durante o horário comercial, no período compreendido entre março a junho de 2006. Na ocasião, foram efetuadas entrevistas com o Gerente de Logística e Tecnologia de Informação (TI) e com o Supervisor de Logística da empresa. O roteiro de entrevista foi elaborado com base em perguntas pertinentes ao assunto, visando atender o objetivo proposto pelo presente artigo; foram também analisados os documentos referentes ao projeto de implementação do RECOF, com o intuito de complementar os dados obtidos com a entrevista, e a observação direta ocorreu no Departamento de TI da empresa no período anteriormente citado.

\section{ESTUDO DE CASO: A IMPLEMENTAC̣ÃO DO RECOF NA DENSO DO BRASIL LTDA.}

O projeto de implementação do RECOF na DENSO do Brasil teve como principal motivação a manutenção da competitividade de seus produtos no mercado. Apesar de a empresa não ser uma grande exportadora, tem nos seus principais clientes uma fonte de exportação indireta, pois pelo próprio conceito do RECOF Compartilhado tudo que é vendido para um cliente que seja habilitado para operar no regime RECOF é considerado como uma exportação indireta, mantendo assim a suspensão dos impostos e transferindo essa suspensão para o cliente, que dependendo do destino do produto se transformará em isenção ou recolhimento dos impostos.

A Figura 2 demonstra o fluxo sistêmico da DENSO do Brasil para atender o regime RECOF. 
Como na maioria das empresas, a DENSO do Brasil tem uma gama de sistemas interligados e que não necessariamente têm o mesmo fluxo exigido pelo Regime RECOF, conforme apresenta a Figura 2. Para que fosse habilitada no regime, foi necessário redefinir e desenvolver todo um sistema de interfaces entre os sistemas para alimentar o sistema "Front end" (RECOF-SYS), adquirido da empresa SOFTWAY (Sistema homologado pela Receita Federal), garantindo assim a qualidade das informações das transações de estoque, estrutura de produtos, dados fiscais, entre outros.

De acordo com o Gerente de Logística e TI, o desenvolvimento do projeto exigiu um número bastante significativo de horas por parte da equipe de TI, para o desenvolvimento das interfaces entre os sistemas e dos usuários, para a adequação dos procedimentos operacionais, sendo:

- Equipe interna de TI da DENSO: 6.000 horas

- Equipe subcontratada de fornecedores: 12.000 horas

- Equipe de usuários da DENSO: 5.000 horas

- Total: 23.000 horas

Os pontos identificados como fatores críticos de sucesso na implementação do RECOF foram:

a) Controle de Material em Processo; b) Baixa automática com base na estrutura dos produtos "Back Flush";

c) Revisão das estruturas de produto para produção, garantindo a correta baixa dos materiais aplicados;

d) Controle dos refugos de matéria-prima e componentes no processo, não podendo exceder a $1 \%$ com isenção de impostos;

e) Controle de Estoque Físico e Contábil com atualização on-line, devendo ser absolutamente iguais;

e) Cadastro de alíquotas de IPI, PIS/ COFINS, IPI atualizado.

O Gerente de TI e Logística afirma que uma das maiores dificuldades é a adequação dos processos internos das montadoras, conforme segue:

Em contato com algumas montadoras é perceptível que, a principal dificuldade na habilitação é a necessidade dessa adequação nos processos internos e controle do material em processo. Principalmente as que estão operando no Brasil há vários anos, com um histórico de transações muito grande e procedimentos operacionais consolidados e muitos deles não escritos. Em uma dessas montadoras, foi afirmado que somente para a adequação dos processos

Figura 2: Fluxo da integração sistêmica para habilitação ao regime RECOF.

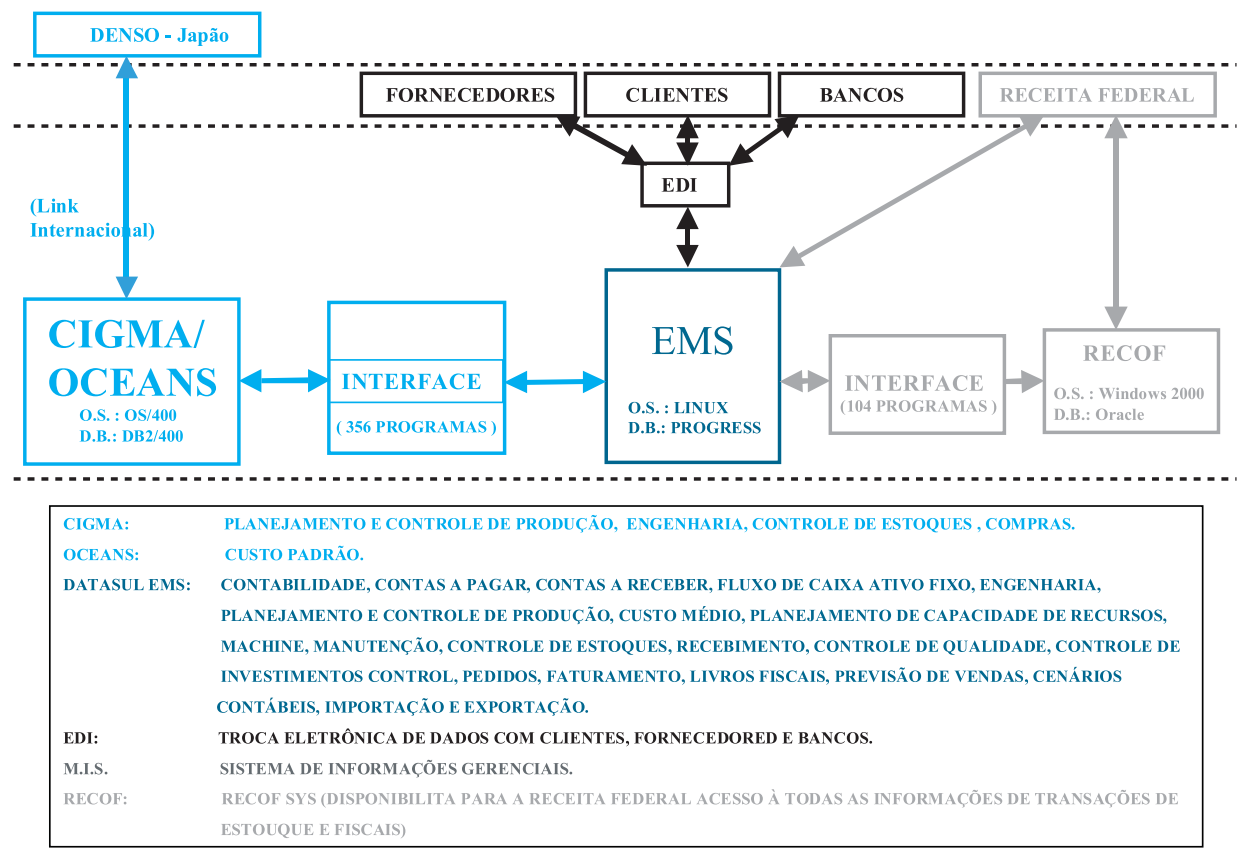

Fonte: Os autores (2005). 
internos seria necessário dois anos, para então iniciar o projeto de implementação do sistema.

A Figura 3 apresenta a situação do processo de habilitação ao regime RECOF automotivo no Brasil até junho 2006 nas montadoras e fornecedores.

É possível perceber através da Figura 3 que apenas uma pequena parte das empresas montadoras e fornecedoras estão habilitadas ao RECOF, o que impossibilita que todos os componentes da cadeia de suprimentos da indústria automobilística obtenham as vantagens logísticas e tributárias com este regime aduaneiro.

A DENSO do Brasil iniciou as operações utilizando os benefícios do regime RECOF em 15 de fevereiro de 2006. Contudo, devido ao baixo número de clientes habilitados que fazem parte da carteira de clientes, não conseguiu ainda ter o retorno esperado na definição do projeto, mas apresenta grandes resultados quanto à redução do estoque de segurança que tradicionalmente, era acrescido para suprir as freqüentes greves da Receita Federal, ou seja foi reduzido em $50 \%$, e, já teve um ganho substancial em aplicação dos valores do impostos suspensos, além dos isentos pelo volume de exportação.

\section{CONSIDERAC̣ÕES FINAIS}

As indústrias automobilísticas buscam constantemente soluções para gerenciar sua cadeia de suprimentos com sucesso, visando obter vantagens competitivas, o que se constitui em um dos seus maiores desafios. Muitas foram as iniciativas neste sentido, desde o aperfeiçoamento de seus sistemas produtivos e logísticos e mais recentemente a necessidade de integração de sua cadeia de suprimentos, o que exige a desburocratização dos processos de negócios, visando a otimização dos recursos empresariais.

$\mathrm{O}$ conceito de gerenciamento da cadeia de suprimentos ambiciona parcerias entre fornecedores e clientes, visando a otimização dos processos logísticos, agregando maior valor aos produtos e serviços das empresas. Ao se analisar o RECOF Automotivo, verifica-se que uma das suas principais características é a necessidade de uma integração intensa entre as empresas, para que toda a cadeia de suprimentos possa alcançar os benefícios do regime. As principais vantagens são representadas pela redução dos custos operacionais da cadeia logística, que envolvem custos com armazenagem; manutenção e controle de estoques; deterioração ou obsolescência dos mesmos e também custos com falta de estoques, sendo estes últimos os mais difíceis de mensurar, além da eliminação da incerteza e a imprevisível disponibilidade dos suprimentos no tempo adequado e redução dos lead-times na entrega do produto final. Outra vantagem importante a ser citada é a redução da necessidade de capital de giro empregado no pagamento de impostos incidentes na compra de matérias-primas e insumos e, em conseqüência, a redução do custo de oportunidade.

A redução dos custos operacionais da cadeia logística é verificada no desembaraço aduaneiro de produtos importados em menor tempo, reduzindo substancialmente a neces-

Figura 3: Situação das habilitações no regime RECOF nas principais montadoras de veículos e fornecedores de auto-peças no Brasil.

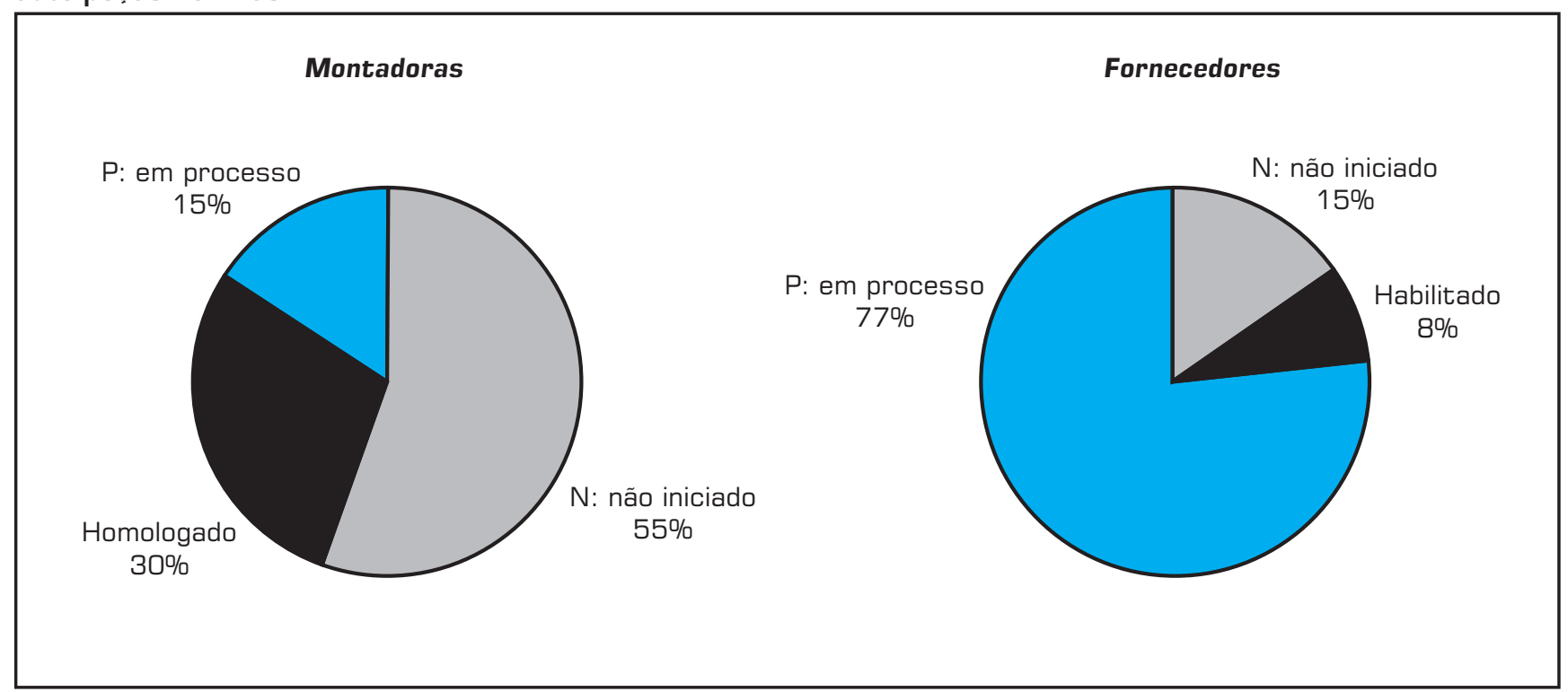

Fonte: Os autores (2006). 
sidade de estoques de segurança, os quais são constituídos para evitar imprevistos futuros, como falta de suprimentos para o atendimento de pedidos dos clientes. A cadeia de suprimentos se torna simplificada a partir do momento em que os gargalos logísticos referentes a estoques são eliminados. Desta forma, as empresas enquadradas no RECOF obtêm vantagem competitiva sustentável.

A redução da necessidade de capital de giro é proporcionada pela manutenção de níveis de estoques baixos (abastecimento Just-in-time) e pela suspensão dos impostos incidentes na compra. Quando se trata de importações para compor produtos destinados à exportação, o Imposto de Importação (II) e o Imposto sobre Produtos Industrializados (IPI) são suspensos. Ao se tratar de aquisição de matériasprimas e insumos nacionais para comporem produtos destinados ao mercado externo, o imposto suspenso é o IPI. Sendo o produto final comprovadamente destinado ao mercado externo, a suspensão do imposto se torna isenção.

Se o produto final composto de produto importado for destinado ao mercado nacional, a suspensão é verificada até o momento em que este é vendido, respeitando o limite de 12 meses. O imposto suspenso que deveria ser pago na compra é devido quando da venda. O mesmo procedimento é verificado quando se trata de produtos composto de produto ou produtos nacionais com suspensão do IPI. O imposto suspenso da compra dos produtos nacionais será devido quando da venda do produto final.

Comparando-se o RECOF com o regime tradicional, verifica-se que a necessidade de capital de giro dispensado na compra de matérias-primas e insumos também é menor pela suspensão dos impostos incidentes.

A redução da necessidade de capital de giro é representada pelo gasto não efetuado nos impostos desde o momento da suspensão na compra da matéria-prima ou insumo até a venda do produto final. Se o destino do produto final for o mercado externo, a necessidade de capital de giro se extingue com a isenção do IPI. Havendo Imposto de Importação em um dos seus componentes este será isentado. Se o destino for o mercado interno, a necessidade do capital de giro para pagamento do IPI e do Imposto de Importação, incidindo sobre algum componente do produto final, inicia-se na venda e termina quando do recebimento da mesma.

A redução do custo de oportunidade é conseqüência da redução dos custos operacionais da cadeia logística e da redução da necessidade de capital de giro. Os valores correspondentes à redução desses custos e à redução da necessidade de capital de giro não apresentarão custos pela oportunidade de a empresa integrar-se ao RECOF. Esses valores podem ser aplicados em alternativas que proporcionem maiores resultados.

\title{
Artigo recebido em 21/06/2006 \\ Aprovado para publicação em 16/10/2007
}

\author{
- Referências \\ ANFAVEA - Associação nacional dos \\ Fabricantes de veículos automotores. \\ Anuário da indústria automotiva brasileira/ \\ brazilian automotive industry Yearbook - \\ 2005 (Exportações/Estatísticas/Carta aos \\ associados). Disponível em: http://www. \\ anfavea.com.br/Index.html. Acesso em: \\ 24 maio 2006. \\ ARBACHE, F. S; SANTOS, A. G.; \\ MONTENEGRO, C.; SALLES, W. F. Gestão \\ de logística, distribuição e trade marketing. \\ Rio de Janeiro: FGV, 2004. \\ BALLOU, R. H. Gerenciamento da cadeia \\ de suprimentos: planejamento, organiza- \\ ção e logística empresarial. Porto Alegre: \\ Bookman, 2004. \\ BALLOU, R. H. Logística Empresarial. São \\ Paulo: Atlas, 1993. \\ BORNIA, A. C. Análise gerencial de custos \\ em empresas modernas. Porto Alegre: \\ Bookman, 2002. \\ BRASIL Decreto Lei $n^{\circ}$ 2.412, de 03 de \\ dezembro de 1997. Institui o Regime \\ Aduaneiro Especial de Entreposto \\ Industrial sob Controle Informatizado \\ - RECOF. Diário Oficial da República \\ Federativa do Brasil, Brasília, 04 de \\ dezembro de 1997. \\ BRITO JUNIOR, I. Análise do impacto lo- \\ gístico de diferentes regimes aduaneiros no \\ abastecimento de itens aeronáuticos empre- \\ gando modelo de transbordo multiproduto \\ com custos fixos. Dissertação apresentada \\ à Escola Politécnica da Universidade \\ de São Paulo para obtenção do grau \\ de Mestre em Engenharia. São Paulo: \\ USP, 2004.
}

CHRISTOPHER, M. Logística e Gerenciamento da cadeia de suprimentos: Estratégias para a redução de custos e melhoria dos serviços. São Paulo: Pioneira, 1997.

DORNIER, P. P.; ERNEST, R.; FENDER, M.; KOUVELIS, P. Global Operations and Logistics: Text and cases. New York: John Wiley \& Sons, 1998.

DUTRA, D. J. S. Uma comparação entre os mecanismos de tributação sobre a produção industrial nos países do Mercosul. $129 \mathrm{f}$. Dissertação (Mestrado em Engenharia da Produção) - Universidade Tecnológica Federal do Paraná. Ponta Grossa, 2006.

HAMAD, R. Modelo para localização de instalações em escala global envolvendo vários elos da cadeia logística. Dissertação apresentada à Escola Politécnica da
Universidade de São Paulo para obtenção do grau de Mestre em Engenharia. São Paulo: USP, 2006.

HARRISON, A.; VAN HOEK, R. Estratégia e gerenciamento de logística. São Paulo: Futura, 2003.

PIRES, S. R. Gestão da cadeia de suprimentos (Supply Chain Management): Conceitos, estratégias, práticas e casos. São Paulo: Atlas, 2004.

LIMA, M. P. Custos logísticos na economia brasileira. Revista Tecnologística. Janeiro/2006. pg. 64 - 69. Disponível em <http://www.centrodelogistica. com.br/new/art_custos_logisticos_economia_brasileira.pdf $>$. Acesso em: 15 jun. 2007. 


\section{- Referências}

PORTUGAL, U. P. Os ganhos logísticos com o RECOG. Disponível em: <http:/ www.logweb.com.br/artigos/arquivo/ art0001403.htm >. Acesso em: 18 maio 2006.

POZO. H. Administração de recursos materiais e patrimoniais: uma abordagem logística. São Paulo: Atlas, 2002

SALES, A. Descomplicando a logística internacional. Revista Tecnologística. Ano XI - n. 124, p. 44-54, mar. 2006.
SECEX - SECRETARIA DO COMÉRIO EXTERIOR - MINISTÉRIO DO DESENVOLVIMENTO, INDÚSTRIA E COMÉRCIO EXTERIOR. Drawback. Disponível em <http://www.mdic.gov. br/sitio/secex/secex/competencia.php >

Acesso em: 27 out. 2006.

SILVA, E. L. \& MENEZES, E. M. Metodologia da Pesquisa e Elaboração de Dissertação. Florianópolis: UFSC, 2001.
SRF - SECRETARIA DA RECEITA FEDERAL - MINISTÉRIO DA FAZENDA. Disponivel em < http://www.receita.fazenda.gov.br/ aduana/Drawback/regime.htm > . Acesso em: 25 out. 2006

SRF - SECRETARIA DA RECEITA FEDERAL. IN SRF $n^{\circ} 254$, de 11 de dezembro de 2002. Dispõe sobre o Regime Aduaneiro Especial de Entreposto Industrial sob Controle Informatizado para a Indústria Automotiva. Diário Oficial da República Federativa do Brasil, Brasília, 12 de dezembro de 2002.

WANKE, P. Logística, gerenciamento da cadeia de suprimentos e organização do fluxo de produtos. In: FIGUEIREDO, K. F.; FLEURY, P. F.; WANKE, P. Logística e gerenciamento da cadeia de suprimentos: Planejamento do fluxo de produtos e dos recursos. São Paulo: Atlas, 2003

\section{- Agradecimentos}

Os autores agradecem à Capes pelo apoio financeiro e à empresa DENSO do Brasil pelas informações prestadas, que possibilitaram a elaboração do presente trabalho.

\section{- Sobre os autores}

\section{Patrícia Guarnieri}

Mestranda do curso de pós-graduação stricto sensu em Engenharia da Produção (UTFPR - Campus Ponta Grossa/PR); Especialista em Gestão Empresarial (UNIVEL-PR); Especialista em Docência no Ensino Superior (UNIPAN-PR); Graduada em Ciências Contábeis (UNIOESTE-PR), Professora colaboradora (UEPG-PR) e bolsista da Capes.

End.: Rua Goiás, 400, Ap. 14 - Ed. Harmonia - Bairro Órfãs - CEP 84010-650 - Ponta Grossa - PR

Tel: (42) 9104-1500, (42) 3222-7763

E-mail: pgguarnieri@yahoo.com.br

\section{Luiz Olívio Bortolli}

Mestrando do curso de pós-graduação stricto sensu em Engenharia da Produção (UTFPR - Campus Ponta Grossa/PR); Graduado em Administração Empresarial na Fundação de Estudos Sociais do Paraná. Presidente do Instituto de Desenvolvimento Social e Cidadania (IBDESC) e diretor da Associação das Empresas da cidade industrial de Curitiba - PR (AECIC).

End.: Av Monteiro Lobato, x/n, km 04 - cx postal 20 - CEP 84016-210 - Ponta Grossa - PR

Tel.: (42) 3220-4805

E-mail: obortolli@hotmail.com

\section{Divonsir de Jesus da Silva Dutra}

Mestre em Engenharia da Produção (UTFPR - Campus Ponta Grossa/PR); Especialista em Gestão Industrial (UTFPR - Campus Ponta Grossa); Graduado em Economia (UEPG). Consultor do SEBRAE

End.: Av Monteiro Lobato, x/n, km 04 - cx postal 20 - CEP 84016-210 - Ponta Grossa - PR

Tel.: (42) 3229-4318, (42) 9972-2637

E-mail: divonsirdutra@yahoo.com.br

\section{Kazuo Hatakeyama}

Doutor em Engenharia Mecânica, University of Wales - UK, pós-doutor em Administração do Ensino Superior, University of Manchester - UK, coordenador e professor do programa de pós-graduação em Engenharia da Produção (UTFPR - Campus Ponta Grossa/PR).

End.: Av. Monteiro Lobato, s/n, km 4 - cx postal 20 - CEP 84016-210 - Ponta Grossa - PR.

Tel.: (42) 3220-4805

E-mail: hatakeyama@utfpr.edu.br 